\title{
Het toelatingsexamen 'Arts en Tandarts' in Vlaanderen: een analyse op het niveau van vakken en universiteiten
}

\author{
T. Buyse, F. Lievens
}

\section{Samenvatting}

Inleiding: In Vlaanderen bestaat sinds 1997 een toelatingsexamen 'Arts en Tandarts'. Voorgaande studies laten zien dat de toetsen over wetenschapsvakken en de redeneerproef een goede voorspellende kracht bezitten in tegenstelling tot het arts-patiëntgesprek. Een nadeel van voorgaande studies was dat het globale eindresultaat in de eerste kandidatuur als criterium fungeerde. Daarom onderzoekt deze studie de voorspellende waarde op een gedetailleerder manier waarbij de uitslagen op de verschillende vakken bij iedere universiteit afzonderlijk als criterium fungeren.

Methode: De steekproef omvat een groep medische studenten die slaagden voor het toelatingsexamen en die voor het academiejaar 2000-2001 een eindresultaat behaalden in hun eerste kandidatuur. Alleen universiteiten met meer dan vifftig studenten werden in de analyses opgenomen. Drie universiteiten met samen 272 studenten namen deel aan het onderzoek. Predictoren in deze studie zijn de scores op de proeven van het toelatingsexamen (biologie, fysica, scheikunde, wiskunde, redeneerproef, stilleestekst en arts-patiëntgesprek). Als criteria fungeren de scores op de vakken en de totaalscore in de eerste kandidatuur.

Resultaten: De wetenschapsproeven van het toelatingsexamen blijken goede predictoren te zijn voor de wetenschapsvakken in de opleiding. De correlatie met de totaalscore in de eerste kandidatuur is hoog. Het arts-patiëntgesprek correleert hoog met het enige klinische vak in de opleiding.

Algemene conclusie: Het toelatingsexamen is een valide voorspeller van toekomstig academisch succes in de opleidingen geneeskunde en tandheelkunde. Niettegenstaande het artspatiëntgesprek in voorgaande studies geen voorspellende kracht had voor de totaalscore in de eerste kandidatuur, is er wel degelijk een hoge correlatie met een klinisch vak in de eerste kandidatuur. (Buyse T, Lievens F. Het toelatingsexamen 'Arts en Tandarts' in Vlaanderen: een analyse op het niveau van vakken en universiteiten. Tijdschrift voor Medisch Onderwijs 2003;22(1):10-17.)

\section{Inleiding}

Door diverse omstandigheden is het soms niet mogelijk om alle studenten tot een bepaalde studierichting in het hoger onderwijs toe te laten. Een beperking van het aantal studenten is bijvoorbeeld onvermijdelijk wanneer afgestudeerden in een bepaalde studierichting slechts beperkte kansen hebben op de arbeidsmarkt, wanneer de studierichtingen financieel te duur zijn of wanneer een hoge opleidingskwaliteit slechts gegarandeerd kan worden voor een beperkt aantal studenten. Indien beleidsmakers ervoor gekozen hebben om het aantal studenten te beperken, hebben zij verschillende alternatieven om een selectie door te voeren. De studenten kunnen onder meer geselecteerd worden door middel van een toelatingsexamen of door een lotingsysteem.

Bij selectie van medische studenten door middel van een toelatingsexamen 
worden traditioneel cognitieve voorspellers zoals vroegere schoolresultaten, kennis van wetenschappen, (non-)verbale en numerieke intelligentie en andere cognitieve capaciteiten gebruikt. ${ }^{1-4}$ Over het algemeen zijn deze cognitieve variabelen goede voorspellers van latere academische prestaties van medische studenten. Dit geldt vooral in de preklinische jaren van de opleiding. ${ }^{5-7}$ Cognitieve variabelen kunnen echter niet alle variantie in academische prestaties van medische studenten verklaren. Volgens Walton omvatten zij slechts $35 \%$ van de te verklaren variantie. ${ }^{8}$ Daarom worden naast cognitieve voorspellers ook vaak niet-cognitieve factoren als selectiecriteria in een toelatingsexamen opgenomen. Met behulp van persoonlijkheidsvragenlijsten en interviews wordt bijvoorbeeld geprobeerd om de motivatie en persoonlijkheidskenmerken van toekomstige medische studenten in kaart te brengen. ${ }^{5}$ 9-12

Sinds 1997 bestaat ook in Vlaanderen een toelatingsexamen voor studenten die de opleiding geneeskunde en tandheelkunde willen aanvatten. Net zoals vele examens in andere landen meet dit examen de cognitieve capaciteiten van de kandidaten. Zo toetst dit toelatingsexamen de kennis en inzicht in vier wetenschapsvakken (biologie, fysica, scheikunde en wiskunde). Daarnaast wordt het inzichtelijk redeneervermogen van de deelnemers getoetst. Het toelatingsexamen bevat tot slot ook twee simulaties. De studenten worden bevraagd over een tekst, die zij eerst in stilte instuderen en over een op video opgenomen gesprek tussen een arts en een patiënt. Lievens en Coetsier beschrijven uitvoerig de verantwoording, de opbouw en de validering van deze twee proeven. ${ }^{13}$

De stilleestekst en het arts-patiëntgesprek simuleren situaties waarmee de kandidaten later in hun medische opleiding en in hun beroep kunnen geconfronteerd worden. Het gebruik van simulaties in een toelatingsexamen voor medische studenten is ongebruikelijk. De simulaties werden aan het examen toegevoegd om te vermijden dat alleen kandidaten met hoge scores voor de cognitieve proeven zouden slagen en tot de opleiding zouden worden toegelaten. Deze proeven (en dan vooral het arts-patiëntgesprek) willen niet enkel cognitieve vaardigheden maar ook interpersoonlijke capaciteiten meten. De kandidaten verwerven via deze simulaties een realistisch beeld van de medische opleiding en van het beroep van (tand)arts. Het is inderdaad zo dat de deelnemende kandidaten deze proeven positief percipiëren en evalueren. Op deze manier 'promoten' deze toetsen het toelatingsexamen. ${ }^{14}$

In vroegere studies over de predictieve validiteit van het toelatingsexamen in Vlaanderen werd het eindresultaat in de eerste kandidatuur voor alle universiteiten in Vlaanderen als criterium gebruikt. 1415 De resultaten van deze studies toonden aan dat de redeneerproef een correlatie had van $.33(\mathrm{p}<.01 ; \mathrm{N}=609)$ met het eindresultaat in de eerste kandidatuur in 1997. Verder kwam naar voren dat de wetenschapsvakken goede predictoren waren voor de academische prestaties van medische studenten. Zo had de score op wiskunde in 1998 een correlatie van .34 met de totaalscore in de eerste kandidatuur en de score voor fysica een correlatie van .33 met de totaalscore in de eerste kandidatuur ( $\mathrm{p}<.01$; $\mathrm{N}=339$ ). Opmerkelijk was dat in geen enkele van deze voorgaande studies bevestiging werd gevonden voor de predictieve validiteit van het arts-patiëntgesprek. In 1998 had de score voor het gesprek bijvoorbeeld een niet-significante correlatie van .10 met de score in de eerste kandidatuur ( $\mathrm{N}=339)$. 
In deze vroegere studies fungeerde het eindresultaat in de eerste kandidatuur als criterium. Een belangrijk probleem met het eindresultaat als criterium komt voort uit het feit dat deze eindscore op verschillende manieren wordt bepaald omdat de feitelijke invulling van deze eerste kandidatuur (wat universiteiten, vakken en docenten betreft) verschilt van universiteit tot universiteit. Deze heterogeniteit binnen het criterium kan misschien verklaren waarom teleurstellende resultaten voor het arts-patiëntgesprek werden gevonden. Het zou bijvoorbeeld kunnen dat scores voor het arts-patiëntgesprek wel een significante correlatie hebben met een niet-klinisch vak in de eerste kandidatuur. Doordat dit niet-klinisch vak slechts een beperkt aandeel (ten opzichte van de wetenschapsvakken) heeft in de einduitslag in de eerste kandidatuur is de correlatie tussen scores voor het arts-patiëntgesprek en de einduitslag in de eerste kandidatuur echter niet significant.

Daarom onderzoekt deze studie de voorspellende waarde van het toelatingsexamen op een meer gedetailleerde manier. Als criterium fungeert niet enkel het eindresultaat in de eerste kandidatuur (zoals in voorgaande studies) maar ook de uitslagen voor de aparte vakken in de eerste kandidatuur geneeskunde. Bovendien evalueren wij ook iedere universiteit afzonderlijk. Deze gedetailleerde analyse per vak (en per universiteit) laat toe om een beter verband te leggen tussen de predictoren (scores op delen van het toelatingsexamen) en de criteria. De hypothesen waren:

- Hypothese 1. De toetsen over de wetenschapsvakken van het toelatingsexamen zullen fungeren als significante predictoren voor de wetenschapsvakken in de eerste kandidatuur geneeskunde (anatomie, fysica, scheikunde, biologie, et cetera).
- Hypothese 2. De stilleestekst zal fungeren als een significante predictor voor alle niet-klinische vakken in de eerste kandidatuur geneeskunde.

- Hypothese 3. Het arts-patiëntgesprek van het toelatingsexamen zal fungeren als een significante predictor voor de klinische vakken in de eerste kandidatuur geneeskunde (stage, communicatietechnieken, gespreksvaardigheden, et cetera).

\section{Methode}

\section{Onderzoekspopulatie}

In juli 2000 namen 1160 kandidaten deel aan het toelatingsexamen 'Arts en Tandarts' (403 mannen en 757 vrouwen, of 34.7 en $65.3 \%$ ). Er slaagden 519 kandidaten (208 mannen en 311 vrouwen of 40.1 en $59.9 \%$ ). Voor onze studie naar de predictieve validiteit van het toelatingsexamen konden data gebruikt worden van studenten die tijdens het aansluitend academiejaar (2000-2001) daadwerkelijk gestart waren in de eerste kandidatuur geneeskunde of tandheelkunde en die er een officieel eindresultaat behaalden. Dit waren 425 kandidaten (171 mannen en 254 vrouwen, respectievelijk 40.2 en $59.8 \%)$.

Verder namen we enkel de universiteiten met meer dan vijftig studenten in de analyses op. Dit waren drie universiteiten met samen 272 studenten in de richting geneeskunde (108 mannen en 164 vrouwen). 257 studenten hadden de Belgische, 14 de Nederlandse en 1 de Luxemburgse nationaliteit. Om de anonimiteit te waarborgen, noemen wij deze drie universiteiten $\mathrm{X}, \mathrm{Y}$ en $\mathrm{Z}$.

\section{Procedure van het toelatingsexamen}

In 2000 werd het toelatingsexamen 'Arts en Tandarts' op één dag plenair georgani- 
seerd in een grote zaal in Brussel. In de voormiddag werden de vier wetenschapsproeven afgenomen. Dit deel werd Kennis en Inzicht in Wetenschappen (KIW) genoemd. De kandidaten kregen 180 minuten de tijd om per vak tien vragen op te lossen. Zij mochten de beschikbare tijd naar eigen voorkeur verdelen over de veertig vragen. Per vraag waren er telkens vier antwoordalternatieven.

$\mathrm{Na}$ de middag stonden de redeneerproef, de stilleestekst en het arts-patiëntgesprek op het programma. Dit deel werd Informatie Verwerven en Verwerken (IVV) genoemd. Voor de redeneerproef kregen de kandidaten vijftig minuten de tijd om vijftig vragen op te lossen. Er waren telkens vijf antwoordalternatieven per vraag. Ook voor de stilleestekst waren er vijftig minuten voorzien. Deze proef omvatte dertig vragen. Hier waren er per vraag vier alternatieven. De kandidaten kregen de aanbeveling de tekst eerst volledig te lezen en pas daarna de vragen te beantwoorden. Daarbij konden zij, zo dikwijls als nodig, de tekst raadplegen. Tot slot werd het op video opgenomen artspatiëntgesprek getoond. Het afnemen van deze proef duurde ongeveer veertig minuten. Telkens werd een fragment uit een consultatie tussen een arts en een patiënt getoond. Daarna kregen de kandidaten één of twee vragen over dit fragment. Per vraag kregen zij 25 seconden oplossingstijd. Deze toets omvatte dertig vragen. Ook hier waren er vier antwoordmogelijkheden per vraag. Om te slagen voor het examen dienden de kandidaten zowel op KIW als op IVV een score van tien op twintig te behalen en op de twee onderdelen samen dienden zij gemiddeld twaalf op twintig te scoren. Dit was bij wetgeving bepaald.

\section{Variabelen}

\section{Predictoren}

In deze studie fungeren de scores voor de verschillende onderdelen van het toelatingsexamen 'Arts en Tandarts' als predictoren. Voor elk van de zeven proeven van het toelatingsexamen werd een totaalscore berekend door het aantal juiste antwoorden op te tellen. Er werd telkens een milde giscorrectie toegepast (-0.1). De scores op de vier wetenschapsvakken werden tot één score herleid (KIW) wegens hun hoge intercorrelaties. De mediaancorrelaties zijn voor universiteit $\mathrm{X}, \mathrm{Y}$ en $\mathrm{Z}$ respectievelijk .36, .36 en .27 (interne consistentiecoëfficiënten zijn .71 voor universiteit $\mathrm{X}, .69$ voor universiteit $\mathrm{Y}$ en .69 voor universiteit Z).

\section{Criteria}

Naast het eindresultaat fungeren ook de scores voor de verschillende vakken in de eerste kandidatuur als criterium. De meeste vakken worden aan de drie universiteiten gedoceerd. Daarnaast zijn er nog een paar specifieke vakken per universiteit. De studenten kunnen op alle vakken een score halen van nul tot twintig. Ook het totaalresultaat is herleid tot een score op een schaal van nul tot twintig.

\section{Resultaten}

\section{Scores voor het toelatingsexamen}

Tabel 1 presenteert de beschrijvende statistieken van de zeven onderdelen van het toelatingsexamen, de totaalscore voor het toelatingsexamen en het eindresultaat in de eerste kandidatuur. Het betreft hier de resultaten voor alle universiteiten samen. De 272 studenten uit deze studie scoorden het best voor de proef biologie (gemiddeld 6.78 op een schaal van tien). De stilleestekst bleek het moeilijkst. De studenten 
Tabel 1. Beschrijvende statistieken van de variabelen van deze studie. N varieert van 270 tot 272.

\begin{tabular}{|c|c|c|c|c|c|c|c|c|c|c|c|}
\hline & $x$ & SD & 1 & 2 & 3 & 4 & 5 & 6 & 7 & $8^{a}$ & $9^{b}$ \\
\hline 1. Biologie & 6.78 & 1.71 & - & & & & & & & & \\
\hline 2. Fysica & 5.95 & 1.93 & $.32^{* *}$ & - & & & & & & & \\
\hline 3. Scheikunde & 4.83 & 1.77 & $.39^{* *}$ & $.39^{* *}$ & - & & & & & & \\
\hline 4. Wiskunde & 5.05 & 2.02 & $.31^{* *}$ & $.34^{* *}$ & $.30^{* *}$ & - & & & & & \\
\hline 5. Redeneerproef & 6.45 & 4.10 & $.18^{* *}$ & $.23^{* *}$ & $.21^{* *}$ & $.20^{* *}$ & - & & & & \\
\hline 6. Stilleestekst & 4.63 & 3.63 & .06 & .08 & $.18^{* *}$ & .12 & $.17^{* *}$ & - & & & \\
\hline 7. Arts-patiëntgesprek & 5.70 & 2.50 & .06 & -.01 & .02 & .08 & -.01 & .08 & - & & \\
\hline 8. Totaal toelatingsexamen ${ }^{a}$ & 12.49 & 3.20 & $.63^{* *}$ & $.66^{* *}$ & $.69^{* *}$ & $.67^{* *}$ & $.46^{* *}$ & $.43^{* *}$ & $.22^{* *}$ & - & \\
\hline 9. Eindscore 1ste kandidatuurb & 13.68 & 2.19 & $.30^{* *}$ & $.24^{* *}$ & .11 & $.30^{* *}$ & .04 & .05 & .14 & $.34^{* *}$ & - \\
\hline
\end{tabular}

a Deze totaalscore werd verkregen door de scores voor de afzonderlijke proeven bij elkaar op te tellen.

b De correlaties tussen de proeven van het toelatingsexamen en de score na de eerste kandidatuur zijn gecorrigeerd voor spreidingsbreedte (Thorndike, 1949, case 2). ${ }^{16}$ Statistische significantie werd bepaald voordat de correctie werd toegepast.

* $\mathrm{p}<.05$.

** $\mathrm{p}<.01$.

behaalden hier slechts een gemiddelde score van 4.63 op een schaal van tien. De gemiddelde totaalscore voor het toelatingsexamen is 12.49 op een schaal van nul tot twintig. De standaarddeviaties van de wetenschappen (van 1.7 tot 2) liggen lager dan die van de andere drie proeven (van 2.5 tot 4.1).

\section{Voorspellende waarde}

In het kader van de onderzoeksvragen, berekenden wij correlaties tussen de scores voor de verschillende proeven van het toelatingsexamen en de resultaten op de vakken en het eindresultaat in de eerste kandidatuur geneeskunde. Deze correlaties bevinden zich in tabel 2 voor de drie universiteiten afzonderlijk. We corrigeerden deze correlaties voor spreidingsbreedte. ${ }^{16}$

Hypothese 1 wordt bevestigd. Tabel 2 laat zien dat de wetenschapsvakken van het toelatingsexamen positief en hoog correleren met de wetenschapsvakken in de opleiding geneeskunde. Dit geldt voor de drie universiteiten. Zo is er bijvoorbeeld een correlatie van .46 ( $\mathrm{p}<.01)$ en .26 $(\mathrm{p}<.01)$ tussen de vier wetenschappen van het toelatingsexamen (KIW) en het vak anatomie, een correlatie van .51 ( $<$ <.001) en $.45(\mathrm{p}<.01)$ tussen KIW en fysica, een correlatie van $.46(\mathrm{p}<.01)$ en $.36(\mathrm{p}<.001)$ tussen KIW en het vak scheikunde en een correlatie van $.49(\mathrm{p}<.001)$ en $.22(\mathrm{p}<.05)$ tussen KIW en het vak biologie. De score voor de vier wetenschapsproeven heeft ook een hoge correlatie met de eindscore in de eerste kandidatuur in de drie universiteiten $(r=.29, r=.58$ en $r=.36)$.

Wij vonden geen bevestiging voor Hypothese 2. Er is geen enkele significante correlatie tussen de stilleestekst en een vak in de eerste kandidatuur van de opleiding geneeskunde. Hypothese 3 wordt wel bevestigd. In de universiteit waar men in de eerste kandidatuur een klinisch vak doceert, is er een significante positieve correlatie van $.38(\mathrm{p}<.05)$ tussen het artspatiëntgesprek en dit vak. In dezelfde universiteit is er ook een positieve correlatie tussen het gesprek en het eindresultaat in de eerste kandidatuur.

Tot slot constateren wij dat de eindscore die de studenten halen voor het toelatingsexamen, een goede predictor is voor 
Tabel 2. Correlaties tussen onderdelen van het toelatingsexamen en vakken in de eerste kandidatuur geneeskunde in Universiteiten $X, Y$ en $Z{ }^{a}$

\begin{tabular}{|c|c|c|c|c|c|}
\hline & KIWb & Redeneerproef & Stilleestekst & Arts-patiëntgesprek & $\begin{array}{l}\text { Totaalscore } \\
\text { toelatingsexamen }\end{array}$ \\
\hline \multicolumn{6}{|c|}{ Universiteit $X(N$ varieert van 114 tot 127$)$. } \\
\hline Anatomie & $.26^{* *}$ & -.03 & .12 & -.18 & $.26^{*}$ \\
\hline Epidemiologie & $.40^{* *}$ & .05 & .06 & .19 & $.43^{* *}$ \\
\hline Celbiologie 1 & $.30^{* *}$ & -.05 & .05 & .03 & $.30^{* *}$ \\
\hline Celbiologie 2 & .19 & .15 & .08 & .01 & $.23^{*}$ \\
\hline Fysica & $.51^{* * *}$ & -.12 & -.04 & -.07 & $.44^{* *}$ \\
\hline Scheikunde & $.36^{* * *}$ & .01 & .02 & .10 & $.36^{* *}$ \\
\hline Biologie & $.22^{*}$ & .04 & .10 & -.08 & $.23^{*}$ \\
\hline Totaalscore 1ste kandidatuur & $.29^{* *}$ & -.03 & .11 & .03 & $.30^{* *}$ \\
\hline \multicolumn{6}{|c|}{ Universiteit $\mathrm{Y}(\mathrm{N}$ varieert van 50 tot 52$)$} \\
\hline Anatomie & $.46^{* *}$ & .11 & -.27 & .29 & $.39^{*}$ \\
\hline Biologie & $.49^{* * *}$ & .10 & -.01 & .19 & $.46^{* *}$ \\
\hline Cel- en weefselleer & $.45^{* *}$ & .23 & .03 & .20 & $.47^{* *}$ \\
\hline Chemie & $.46^{* *}$ & .15 & -.03 & .21 & $.45^{* *}$ \\
\hline Fysica, wiskunde & $.45^{* *}$ & .10 & .02 & .12 & $.43^{*}$ \\
\hline Training, stage & -.13 & -.05 & -.02 & $.38^{*}$ & -.05 \\
\hline Totaalscore 1ste kandidatuur & $.58^{* *}$ & .19 & .05 & .21 & $.57^{* *}$ \\
\hline
\end{tabular}

Universiteit $\mathrm{Z}(\mathrm{N}$ varieert van 92 tot 93$)$

\begin{tabular}{|c|c|c|c|c|c|}
\hline Celbiologie 1 & $.41^{* *}$ & .21 & .02 & .17 & $.40^{* *}$ \\
\hline Celbiologie 2 & $.39^{* *}$ & .18 & -.05 & .22 & $.37^{* *}$ \\
\hline Informatieverwerking & .09 & .05 & .03 & $.44^{* *}$ & .16 \\
\hline Celbiologie 3 & $.26^{*}$ & .19 & -.04 & $.29^{*}$ & $.28^{*}$ \\
\hline Infectie en afweer & $.47^{* *}$ & .15 & .18 & .21 & $.50^{* *}$ \\
\hline Exploratie & .15 & -.08 & -.14 & .13 & .09 \\
\hline Gezondheid & .03 & .06 & -.07 & .19 & .05 \\
\hline Totaalscore 1ste kandidatuur & $.36^{* *}$ & .15 & .00 & $.33^{* *}$ & $.38^{* *}$ \\
\hline
\end{tabular}

a De correlaties zijn gecorrigeerd voor spreidingsbreedte (Thorndike, 1949, case 2). ${ }^{16}$ Statistische significantie werd bepaald vooraleer de correctie werd toegepast.

b $\quad \mathrm{KIW}=$ De som van de scores voor de proeven biologie, fysica, scheikunde en wiskunde, herleid tot een score op 20.

* $\mathrm{p}<.05$.

** $\mathrm{p}<.01$.

*** $\mathrm{p}<.001$.

de scores van die studenten voor alle vakken in de eerste kandidatuur. Uitzonderingen hierop zijn de meer interpersoonlijk, psychologisch gerichte vakken zoals training, stage, informatieverwerking, exploratie en gezondheid. De slaagpercentages in de eerste kandidatuur liggen in de drie universiteiten ook erg hoog. Zo slaagde in universiteit X 93\% van de stu- denten; in universiteit Y slaagde $82 \%$ van de studenten en in universiteit $\mathrm{Z}$ slaagde $87 \%$.

\section{Discussie}

Voorgaande studies naar de predictieve validiteit van het toelatingsexamen 'Arts en Tandarts' gebruikten als criterium het eindresultaat in de eerste kandidatuur. Er 
werd ook geen onderscheid gemaakt tussen de verschillende universiteiten waardoor een analyse op vakniveau niet mogelijk was. Iedere universiteit heeft een eigen opleidingsprogramma en een vergelijking tussen verschillende vakken, gedoceerd door verschillende mensen was dus onmogelijk in voorgaande studies. Daarom is de meerwaarde van deze studie dat wij analyses uitvoerden op het niveau van de vakken. Bovendien bekeken wij de universiteiten afzonderlijk. De predictieve validiteit van alle onderdelen van het toelatingsexamen is op deze manier gedetailleerder in kaart gebracht.

In vorig onderzoek werd reeds herhaaldelijk een hoge correlatie tussen de wetenschapsproeven van het toelatingsexamen en het eindresultaat in de eerste kandidatuur gevonden. ${ }^{14} 15$ Deze studie bevestigt dit resultaat nog eens. Verder vonden wij dat de wetenschapsproeven van het toelatingsexamen ook hoog en positief correleren met de scores voor de wetenschapsvakken in de preklinische jaren van de opleiding geneeskunde.

Tussen de stilleestekst en de vakken in de opleiding geneeskunde vonden wij in deze studie geen verband. Nochtans wordt tijdens de opleiding veel zelfstudie van de studenten verwacht. Dat er geen significante correlaties zijn, zou kunnen toegeschreven worden aan het feit dat de kandidaten op het toelatingsexamen aan een tijdslimiet gebonden zijn. Tijdens de opleiding kunnen zij hun cursussen vaak herhaaldelijk instuderen tijdens het jaar om zo de stof onder de knie te krijgen. Op het toelatingsexamen is dit niet het geval. Er is hoogstens tijd om de tekst eenmaal grondig door te nemen.

Uit voorgaande studies kwam tot uiting dat het arts-patiëntgesprek tot nu toe weinig predictieve validiteit had voor het eindresultaat in de eerste kandidatuur geneeskunde. ${ }^{14} 15$ Hieruit zou men kunnen concluderen dat het beter is om deze proef niet meer af te nemen. Bij analyse op vakniveau blijkt echter dat het gesprek wel degelijk significant en positief correleert met een klinisch vak in de opleiding geneeskunde. Omdat er in de eerste kandidatuur nog niet veel klinische vakken gegeven worden, lijkt het interessant om de analyse op vakniveau ook in een longitudinale studie voor de latere jaren van de opleiding te bekijken (In Vlaanderen duurt de opleiding zeven jaar). Aangezien in de hogere jaren meer interpersoonlijke vakken aan bod komen, is de verwachting dat er ook daar significante positieve correlaties zullen zijn tussen het arts-patiëntgesprek en deze klinische vakken. Toekomstige studies dienen hier uitsluitsel over te geven. Een ander tekort van deze studie is dat studenten die niet toegelaten werden tot de opleiding, buiten beschouwing zijn gelaten. Hierdoor kunnen we geen antwoord geven op de vraag of studenten ten onrechte werden afgewezen.

We kunnen besluiten dat de cognitieve vaardigheden die door de vier wetenschapsproeven van het toelatingsexamen gemeten worden, de latere academische prestaties van de studenten op cognitief vlak voorspellen. De proef die interpersoonlijke capaciteiten meet (het arts-patiëntgesprek), heeft voorspellende waarde ten aanzien van het resultaat op een interpersoonlijk vak in de opleiding.

\section{Literatuur}

1. Green A, Peters TJ, Webster DJT. Preclinical progress in relation to personality and academic profiles. Med Educ 1993;27:137-42.

2. Montague W, Odds FC. Academic selection criteria and subsequent performance. Med Educ 1990;24:44-7.

3. Roessler R, Lester JW, Butler WT, Rankin B, Collins F. Cognitive and non-cognitive variables in the prediction of pre-clinical performance. J Med Educ 1978;52:678-81. 
4. Vu NV, Dawson-Saunders B, Barrows HS. Use of Medical Reasoning Aptitude Test to help predict performance in medical school. J Med Educ 1987;62:325-35.

5. Green A, Peters TJ, Webster DJT. An assessment of academic performance and personality. Med Educ 1991;25:343-8.

6. Mitchell K, Haynes R, Koenig J. Assessing the validity of the updated Medical College Admission Test. Acad Med 1994;69:394-401.

7. Powis DA. Selecting medical students. Med Educ 1994;28:443-69.

8. Walton HJ. Personality assessment of future doctors. J R Soc Med 1987;53:27-30.

9. Hojat M, Robeson M, Damjanov I, Veloski JJ, Glaser K, Gonnella JS. Students' psychosocial characteristics as predictors of academic performance in medical school. Acad Med 1993;68:635-7.

10. Ferguson E, Sanders A, O'Hehir F, James D. Predictive validity of personal statements and the role of the five-factor model of personality in relation to medical training. Journal of Occupational and Organizational Psychology 2000;73:321-44.

11. Elam CL, Johnson MM, Wiese HJ, Studts JL, Rosenbaum M. Admission interview reports: a content analysis of interviewer comments. Acad Med 1994;69:63S-65S.

12. Edwards JC, Johnson EK, Molidor JB. The interview in the admission process. Acad Med 1990;65:167-77.
13. Lievens F, Coetsier P. Een andere kijk op selectie van kandidaat medische studenten: ontwikkeling van op video opgenomen simulaties. Tijdschrift voor Hoger Onderwijs 1998;13:117-30.

14. Lievens F, Coetsier P, Buyse T. Het toelatingsexamen 'Arts en Tandarts' in Vlaanderen: Voorspellende validiteit en reacties van de studenten. Tijdschrift voor Medisch Onderwijs 2001;20:186-95.

15. Lievens F, Coetsier P, Janssen PJ, Decaesteker C. Predictieve validiteit en genderspecificiteit van het toelatingsexamen 'Arts en Tandarts' in Vlaanderen: Een eerste peiling. Pedagogische Studiën 2001;78:4-15.

16. Thorndike RL. Personnel selection: Test and measurement techniques. New York: Wiley; 1949.

De auteurs:

Tine Buyse is wetenschappelijk medewerker aan de Universiteit Gent, tine.buyse@rug.ac.be.

Filip Lievens is universitair hoofddocent aan de Universiteit Gent,filip.lievens@rug.ac.be.

Correspondentieadres:

Tine Buyse \& Filip Lievens, Vakgroep Personeelsbeleid en Arbeids- en Organisatiepsychologie, Universiteit Gent, Henri Dunantlaan 2, 9000 Gent, België, tel: +329 26464 69, fax: +3292646494.

\section{Summary}

Introduction: Since 1997 the admission procedure used by all medical and dental schools in Flanders has consisted of the Admission Examination 'Medical and Dental Studies'. Previous studies showed that the science knowledge tests and the reasoning test were significant predictors of later academic success, but did not find such a relationship for the videotaped physician patient encounter. In this article a more detailed analysis is reported. This analysis also included the scores on the different first-year courses of different universities as additional criterion measures.

Method: The population consisted of 272 medical students from universities with over fifty first-year students who had passed the Admission Examination and had a final first-year score (2000-2001). Predictors were the seven tests of the Admission Examination (biology, physics, chemistry, maths, reasoning test, silent reading protocol and videotaped physician patient encounter). The results on the different first-year courses and the final first-year score of the different universities serve as criterion measures.

Results: The results on the science knowledge tests of the Admission Examination emerged as significant predictors of the scores on non-clinical courses. The correlation with the final first-year result was high. The analysis also revealed a high correlation between the videotaped interaction and the only clinical course in the first year.

General conclusion: The Admission Examination 'Medical and Dental Studies' is a valid predictor of later academic success of medical and dental students. In contrast to previous studies, this study demonstrated a high correlation between the results on the physician patient encounter and the results on clinical courses in the first year. (Buyse T, Lievens F. The Admission Examination 'Medical and Dental Studies' in Flanders: an analysis at the level of courses and universities. Dutch Journal of Medical Education 2003;22(1):10-17.) 